\title{
Size-effect of germanium nanocrystals
}

\author{
Ou, Haiyan; Ou, Yiyu; Liu, Chuan; Berg, Rolf W.; Rottwitt, Karsten
}

\section{Published in:}

Proceedings of CLEO:2011

Publication date:

2011

Link back to DTU Orbit

Citation (APA):

Ou, H., Ou, Y., Liu, C., Berg, R. W., \& Rottwitt, K. (2011). Size-effect of germanium nanocrystals. In Proceedings of CLEO:2011 Optical Society of America. http://www.cleoconference.org/

\section{General rights}

Copyright and moral rights for the publications made accessible in the public portal are retained by the authors and/or other copyright owners and it is a condition of accessing publications that users recognise and abide by the legal requirements associated with these rights.

- Users may download and print one copy of any publication from the public portal for the purpose of private study or research.

- You may not further distribute the material or use it for any profit-making activity or commercial gain

- You may freely distribute the URL identifying the publication in the public portal

If you believe that this document breaches copyright please contact us providing details, and we will remove access to the work immediately and investigate your claim. 


\title{
Size-effect of germanium nanocrystals
}

\author{
Haiyan Ou, ${ }^{1, *}$ Yiyu Ou, ${ }^{1}$ Chuan Liu ${ }^{2}$, Rolf W. Berg ${ }^{2}$ and Karsten Rottwitt ${ }^{1}$ \\ ${ }^{1}$ Department of photonics engineering, Technical university of Denmark, Building 343, DK-2800, Kgs. Lyngby, Denmark \\ ${ }^{2}$ Department of chemistry, Technical university of Denmark, Building 208, DK-2800, Kgs. Lyngby, Denmark \\ "haou@fotonik.dtu.dk
}

\begin{abstract}
Different sizes of Ge nanocrystals embedded in a $\mathrm{SiO}_{2}$ matrix were formed by PECVD, and analyzed by TEM. Size effect of Ge nanocystals was demonstrated by Raman spectroscopy after excluding the thermal effect.

OCIS codes: (160.4236) nanomaterial; (160.6000) semiconductor material;
\end{abstract}

\section{Introduction}

Zero-dimensional germanium (Ge) nanocrystals (ncs) have undergone intensive theoretical and experimental research due to their potential applications as light emitters, non-volatile optical memories and their enhanced thirdorder optical nonlinear effects, etc. Among them, the high-efficiency Ge light emitter application is receiving tremendous attention because $\mathrm{Ge}$ has a direct bandgap $(0.80 \mathrm{eV})$ only slightly larger (by $0.136 \mathrm{eV})$ than its indirect bandgap $(0.664 \mathrm{eV})$, putting Ge emission at high efficiency within the third optical communication window ( $\sim 1520$ $1620 \mathrm{~nm}$ ). It has been reported recently that bulk Ge emits with $10 \%$ efficiency at its direct bandgap wavelength of $1550 \mathrm{~nm}$ by optimized doping and strain implementation [1]. Ge ncs usually shift the emission wavelength to shorter wavelengths because of quantum confinement effect (QCE). Therefore, Ge ncs with combined effects of QCE, doping and strain could be very promising high-efficiency light emitters covering the entire visible and IR wavelength ranges.

\section{Sample Preparation}

Four samples (0126, 0269, 0194 and 0351) have been prepared by using plasma enhanced chemical vapour deposition (PECVD) and annealing. We started with 4 inch (100) oriented Si substrates. First, one layer of Ge doped $\mathrm{SiO}_{2}$ was deposited. Then a SiGe alloy layer was deposited on top of the $\mathrm{SiO}_{2}$ layer. The ratios of the Si to Ge were tuned from 1:1 to 1:0.5 and 1:0.25 for samples 0194, 0269 and 0126 respectively. Thirdly, one identical layer of Ge doped $\mathrm{SiO}_{2}$ was deposited on the SiGe alloy layer. By repeating alternate layers of SiGe alloy layer and Ge doped $\mathrm{SiO}_{2}$ layer, a multilayered structure was readily made during the PECVD deposition. The samples were annealed at $1100{ }^{\circ} \mathrm{C}$ in $\mathrm{N}_{2}$ for 4 hours after deposition. More details of the fabrication parameters are found in [2]. Samples 0126, 0269 and 0194 had 3-layer structures. Sample 0351 had a 5-layer structure with 1:1 Si/Ge ratio, made in order to increase the light-Ge ncs interaction volume .

\section{TEM analysis}

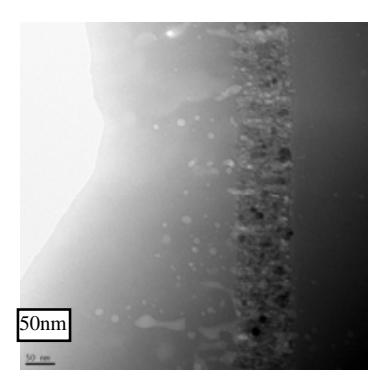

(a) Sample 0126

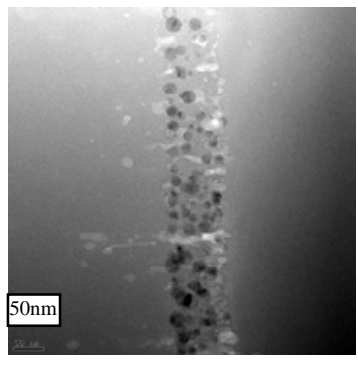

(b) Sample 0269

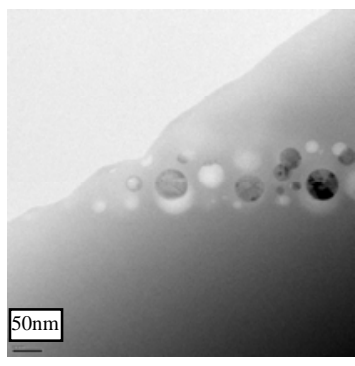

(c) Sample 0194

Fig. 1. TEM cross-sectional images of samples 0126(a), 0269(b) and 0194(c).

The 3 samples (0126, 0269 and 0194) were firstly examined by TEM (by use of a FEI Tecnai G2 apparatus) with focus on size, distribution and crystalline state of the Ge ncs. TEM cross-sectional images of them are shown in Figs. 1 (a), (b) and (c) respectively.

Fig. 1 shows the presence of both Ge ncs (black dots confirmed by high resolution TEM)) and voids (white dots) in the as-deposited SiGe alloy layer, which was sandwiched by the $\mathrm{SiO}_{2}$ layer. For sample 0126, the diameter of the Ge ncs was within $25 \mathrm{~nm}$. Some of the voids even seemed to have diffused to the top surface of the wafer. For sample 0269, both Ge ncs and voids presented themselves with sizes larger than that for sample 0126. The Ge ncs 


\section{JWA60.pdf}

had diameters up to $30 \mathrm{~nm}$. For sample 0194, Ge ncs had variable diameters up to $80 \mathrm{~nm}$. The Ge ncs in all the three samples were crystalline (checked by the dark field image). It can be concluded from Fig.1 that the size of Ge ncs increases as the ratio of $\mathrm{Si} / \mathrm{Ge}$ decreases.

\section{Raman spectroscopy}

The Raman spectra were measured at room temperature by using a "RENISHAW inVia Raman Microscopy" System. It is configured as a backscattering collection setup with a microscope entrance. The system was calibrated by cyclohexane before measurements and the resolution was $\sim 1.3 \mathrm{~cm}^{-1}$. The excitation laser had a wavelength of 488 nm. An X20 objective lens was used. The power was measured by a power meter (Thorlabs PM30-120V) directly under the objective lens and we used $5 \mathrm{~mW}$ of excitation power on most samples.

According to Nataraj et al. [3], the Ge ncs Raman peak shifts linearly with the excitation power density due to the thermal effect. Special attention had been paid to nanocrystals because the Raman signal usually is weak. It is particularly important in the present case because our Ge ncs are embedded in a $\mathrm{SiO}_{2}$ matrix, which has quite poor thermal dissipation. In order to exclude the thermal effect, we measured the Raman spectra of sample 0351 with varied excitation power levels ranging from $1 \mathrm{~mW}$ to $21 \mathrm{~mW}$. The result shows that as excitation power increases, the Ge Raman peak has a downshift and the FWHM increases. At low excitation powers $(<11 \mathrm{~mW})$, there is no linear relationship between the shift and the excitation power. However, at high excitation powers, the heat effect starts to play a dominant role, and a linear relationship is emerging. Therefore, the Raman spectra of samples 0126, 0194, 0269 and 0351 together with a single-crystalline Ge wafer as a reference listed in Fig.2 were recorded by using an excitation power of $5 \mathrm{~mW}$ to reveal the properties for example the size-dependent effect and the strain effect, unbiased by the heat from excitation light illumination. The reference Ge wafer showed a strong Raman peak at $298.6 \mathrm{~cm}^{-1}$. All the other samples showed two distinct peaks: one at around $300 \mathrm{~cm}^{-1}$, corresponding to Ge ncs and one at around $520 \mathrm{~cm}^{-1}$, corresponding to the Si substrate. The appearance of the peak at $300 \mathrm{~cm}^{-1}$ further confirms the formation of Ge ncs, adding to the results from the TEM examination. An enlarged zoom of the Ge peak is inserted in Fig. 2. Compared to the reference Ge wafer, the Ge peaks for the 4 samples are all shifted. Samples 0126, 0269 and 0194 all had upshifts and sample 0351 had a downshift.

Size effects, thermal effects and strain are possible reasons for the peak shifts. Results shown in Fig. 2 may be taken as a proof to exclude the thermal effect. So the shifts are only dependent on size and strain effects. From Fig.2, no simple relationship between the Raman shift and the Ge nanocrystal size seems to be obvious, which implies that the size effect and strain probably are interplayed and difficult to distinguish in this case.

\section{Conclusion}

Ge ncs of different sizes have been successfully formed by tuning the Si/Ge ratio in the as-deposited SiGe alloy layer. The size, distribution and crystalline state of the samples have been investigated by TEM. The existence of the Ge ncs in the $\mathrm{SiO}_{2}$ matrix has been confirmed by both TEM analysis and Raman

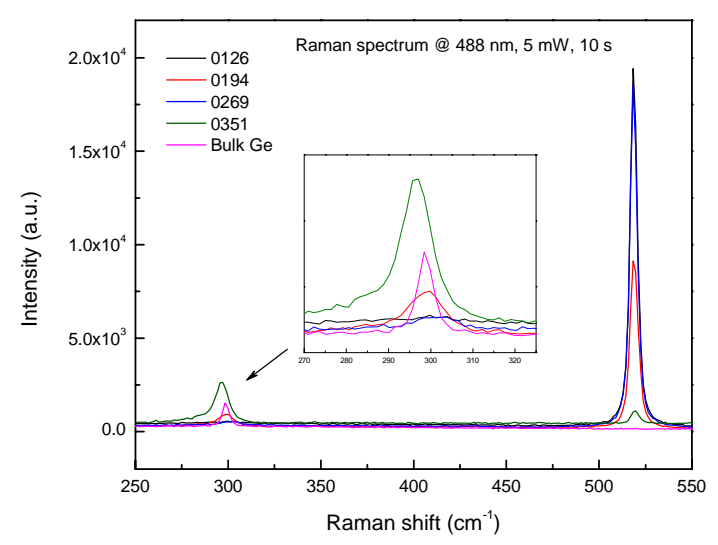

Fig.2. Raman spectra of samples 0126, 0269, 0194, 0351 and the reference Ge wafer. The inset is a zoom-in on the Ge peak. spectroscopy. Suitable low excitation power level for Raman spectroscopy to exclude the thermal effect was selected by measuring the Raman spectra within a large excitation power range from $1 \mathrm{~mW}$ to $21 \mathrm{~mW}$. From Raman measurements, the peak shifts excluding the thermal effect were assigned to interplaying phenomena as size and strain effects.

\section{References}

[1] X. Sun, J. Liu, L. C. Kimerling, and J. Michel, “Toward a Germanium laser for integrated silicon photonics,” IEEE J. Selec. Top. Quant. Electron., 16(1), 124-131 (2010).

[2] H. Ou, T. P. Rørdam, K. Rottwitt, F. Grumsen, A. Horsewell, R. W. Berg, and P. Shi, “Ge nanoclusters in PECVD-deposited glass caused only by heat treatment,” Appl. Phys. B, 91, 177-181 (2008).

[3] L. Nataraj, F. Xu, and S. G. Cloutier, "Direct-bandgap luminescence at room temperature from highly-strained Germanium nanocrystals," Opt. Express, 18(7), 7085-7091 (2010). 